\title{
CORONARY ARTERIO-CAMERAL FISTULA
}

\author{
BY \\ C. S. MUIR \\ From the Department of Pathology, University of Malaya in Singapore
}

Received July 7, 1959

Communication between the coronary arteries and the cardiac chambers is a rare event. In the 22,500 post-mortems performed at the General Hospital, Singapore, over the past decade, there were some 520 cases of congenital heart disease. In this material there were three examples of this unusual anomaly, all occurring in infants of Chinese race.

As about 30 cases of this anomaly have now been described, a more succinct descriptive phrase than "communication between coronary artery and cardiac chamber" seems desirable. To this end, the author suggests "coronary arterio-cameral fistula" (Latin: camera-a vault; hence chamber =an enclosed space in the body of an animal or plant (O.E.D.)). The term coronary arteriovenous aneurysm can thus be reserved for communications between the coronary artery and the coronary veins or sinus.

\section{CASE Reports}

Case 1. W.T.C., a five-month-old male Chinese infant was admitted to the General Hospital, Singapore, with a history of cyanosis since birth. He was dyspnœic and cyanosed; the fingers and toes were clubbed. A rough systolic and diastolic murmur was heard over the præcordium. He died four days after admission.

Necropsy. The lungs were noted to be congested, showing early bronchopneumonia. The heart showed great enlargement of the right side. The right atrium was both dilated and hypertrophied. The right ventricular wall was grossly hypertrophied, being $1.2 \mathrm{~cm}$. thick; the endocardium was thick and white. The right ventricle appeared to be divided into two portions, an anterior and a posterior, by a thick muscular septum in the coronal plane, into the upper surface of which a normal tricuspid valve was inserted. The anterior of these chambers was dilated and led up into a dilated infundibulum at the apex of which was an almost completely stenosed pulmonary valve (Fig. 1). The pulmonary artery was rather smaller in calibre than usual. There was a large patent ductus arteriosus. The left ventricle was normal in morphology, the wall being $0.8 \mathrm{~cm}$. thick. There was a probe-patent foramen ovale.

Arising from the left posterior aortic cusp was a thick-walled coronary vessel ("A"), $2.0 \mathrm{~cm}$. in circumference, which proceeded towards the apex, along the interventricular septum, for some $2.0 \mathrm{~cm}$. (Fig. 1 and 2). At this point, there was a constriction reducing the vessel circumference to $0.5 \mathrm{~cm}$. Beyond the constriction the main vessel regained its former size, and, at once, gave off two smaller branches, which coursed laterally for $1.0 \mathrm{~cm}$. and $0.8 \mathrm{~cm}$. respectively to enter the infundibulum of the right ventricle. The openings of these smaller vessels into the larger were much smaller than their lumina.

The main trunk continued towards the apex for another $1.5 \mathrm{~cm}$., turning laterally for $1.0 \mathrm{~cm}$. before dividing into two, both branches, $0.8 \mathrm{~cm}$. long, terminating in the right ventricular cavity. At the lowest point of this main trunk, a smaller branch ran for $1.8 \mathrm{~cm}$. towards the apex and there divided into two branches; one, entering the substance of the interventricular septum was observed to communicate eventually with the right ventricular cavity; the other continued along the surface of the interventricular septum to the apex.

From the anterior aortic sinus, a right coronary vessel coursed in the right atrio-ventricular groove (Fig. 2). This gave off, at once, a small ventricular branch, then $0.5 \mathrm{~cm}$. from the ostium, a small atrial branch. There was a further ventricular branch; then the main trunk divided into two. The smaller vessel continued normally in the atrio-ventricular groove, the larger (vessel "B"), turning a right angle, ran for $1.0 \mathrm{~cm}$. over the right ventricle before disappearing into the right ventricle. 
Histology. Vessel "A" showed a slight increase in the medial muscle, splitting of the internal elastic lamina, and a great increase in the amount of the medial elastic tissue. Passing through the heart wall, the media was rapidly lost, the intima and internal elastic lamina becoming continuous with the endothelial heart lining.

A section was taken through vessel "B" as it entered the right ventricle (Fig. 3). The vessel wall was of normal thickness. The intima was slightly thicker than normal. The internal elastic lamina was intact; the external was split and greatly reduplicated. There appeared to be more elastic and fibrous tissue in the media than normal, the amount of muscle being correspondingly diminished. As the vessel neared its termination the sub-intima became much thicker, moderate amounts of loose connective tissue making their appearance. The internal elastic lamina became increasingly frayed, although still discernible as an entity. The medial coats became much thicker, containing even larger amounts of elastic tissue and diminishing amounts of muscle. Within the cardiac muscle the vessel walls rapidly diminished in size, the media disappearing after an intramuscular course of some $0.2 \mathrm{~cm}$. The intimal layer continued as an endothelium lined channel which communicated freely with the right ventricle. The wall of this channel showed considerable amounts of elastic tissue. The elastic tissue was most prominent at either side of the opening of the fistulous vessel into the ventricle, at that part of the ventricle opposite the point of debouchement of the abnormal vessel (Fig. 4), and to a lesser extent at the junction of the inter-trabecular sinuses with the ventricular lumen (Square Y in Fig. 3).
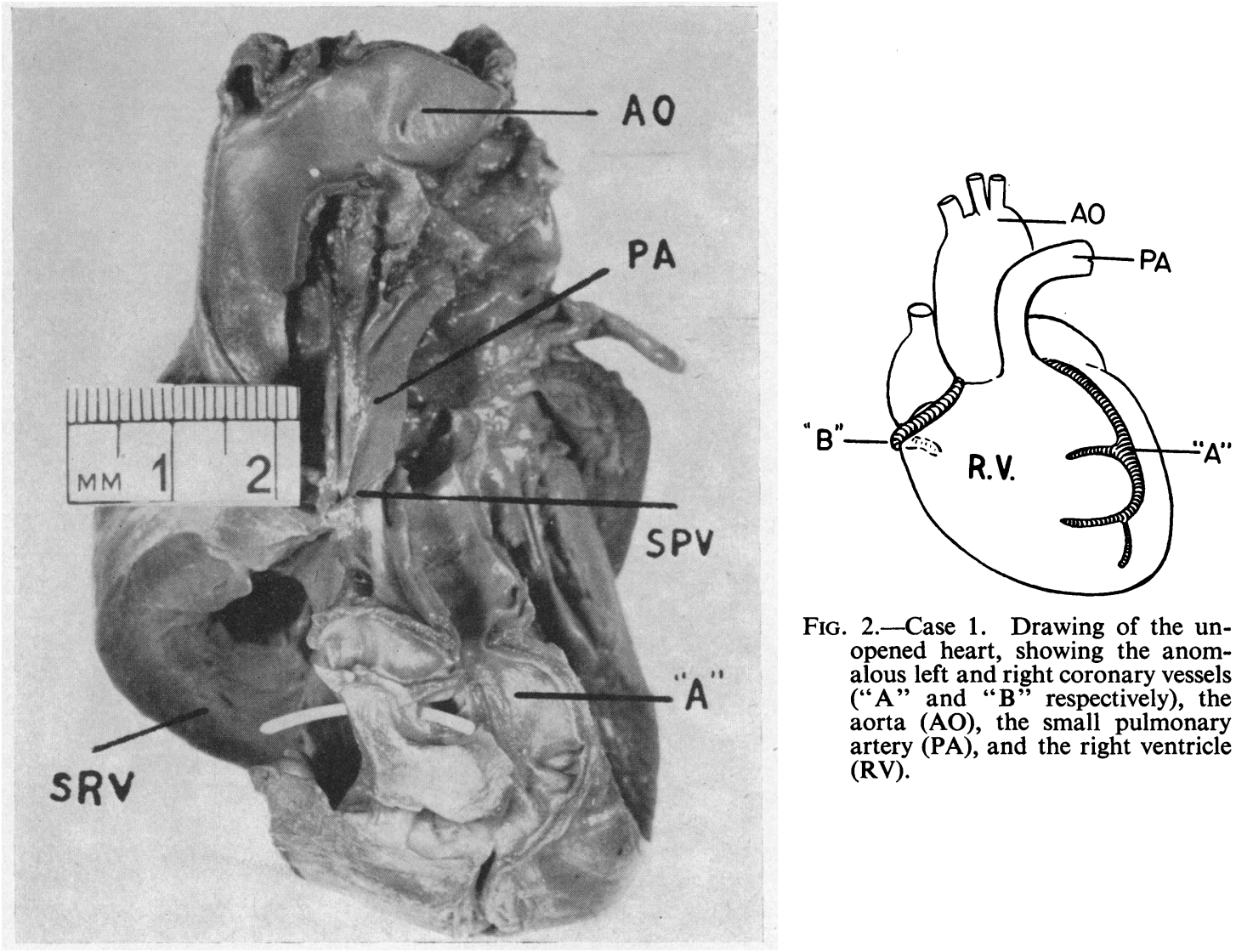

FIG. 2.-Case 1. Drawing of the unopened heart, showing the anomalous left and right coronary vessels ("A" and "B" respectively), the aorta (AO), the small pulmonary artery (PA), and the right ventricle (RV).

Fig. 1.-Case 1. The stenosed pulmonary valve (SPV) and pulmonary artery (PA) lie between the aorta (AO) and the beginning of the wide anomalous left coronary artery "A". Three of the sites of fistula are seen: the white plastic rod lies in the central one. Note the thick wall and the septum across the right ventricle (SRV). 


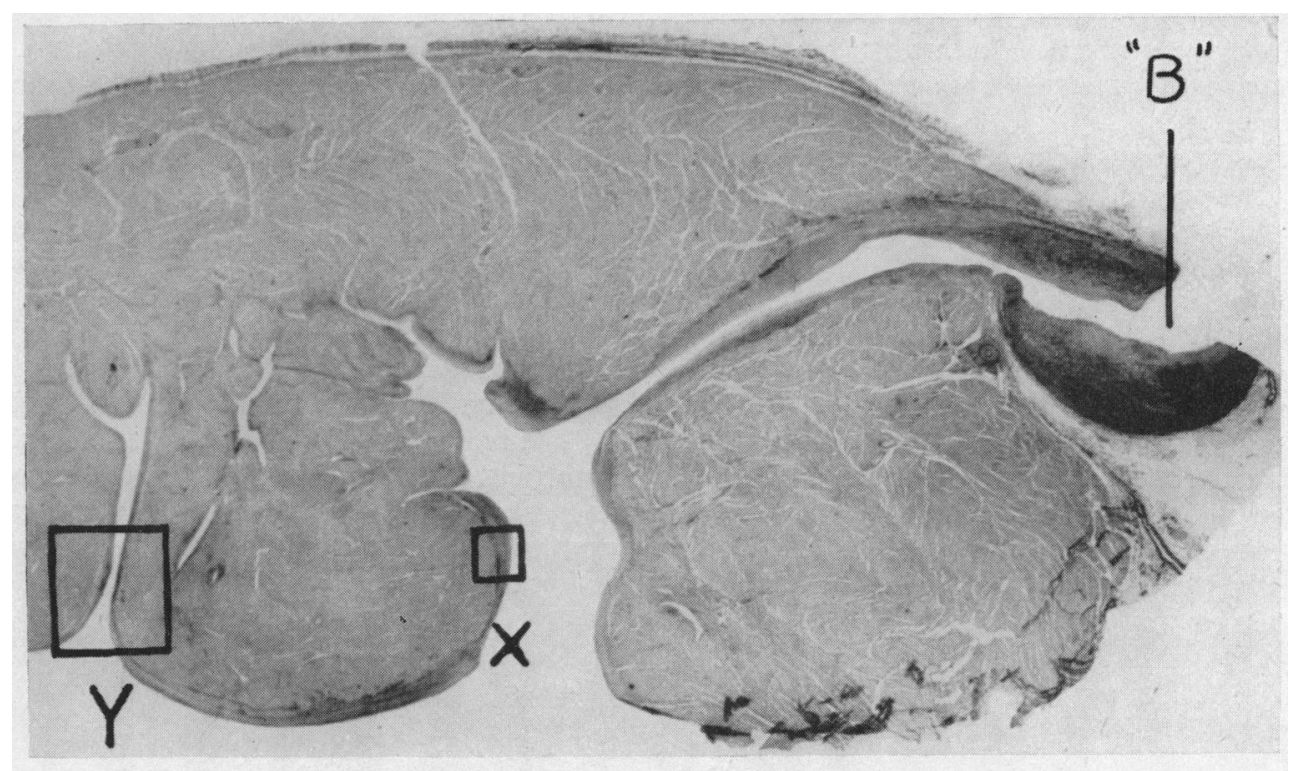

FIG. 3.-Case 1. Section through the right ventricular wall, showing the fistula between vessel "B" and the ventricular lumen. Note the increased elastic tissue in the terminal portion of the artery. (Verhoeff-van Gieson, $\times 6$. .)

There were numerous deep sinuses in the myocardium, easily distinguishable from arteries and veins several of which almost reached the epicardium. The endocardium of the right ventricle showed well-marked fibro-elastosis, in addition to the prominent aggregations of elastic tissue noted above. In a few places the cardiac muscle deep to this fibro-elastic layer showed incipient necrosis, and several small islets of muscle fibres sequestrated by fibrous tissue were noted.

Case 2. C.C.K., a two-month-old Cantonese boy, was admitted to the General Hospital, Singapore. The child, it was claimed, had never been well since birth, and in particular, was noted to become dyspnoic after meals. From time to time he had bouts of coughing and vomiting.

On admission there was cyanosis of the lips and fingers. A loud systolic murmur, which was heard all over the chest, seemed maximal in intensity at the mitral area. The liver was palpable one fingerbreadth below the costal margin. The child died five days after admission.

Necropsy. The right atrium was slightly dilated. The interatrial septum showed three defects, each about $0.8 \mathrm{~cm}$. in diameter. The tricuspid orifice was rather small measuring $0.6 \mathrm{~cm}$. across; the tricuspid valve leaflets were normal. The right ventricular cavity was very small, the wall being $0.9 \mathrm{~cm}$. thick. There was a pulmonary valvular atresia, the outlines of the fused cusps being clearly visible. The lungs were supplied via a large patent ductus arteriosus.

The left ventricle and left coronary artery were normal. The right coronary artery began at the apex of a funnel-shaped aneurysmal dilatation of the anterior sinus of Valsalva. This measured $0.9 \mathrm{~cm}$. across at the beginning, tapering over a distance of $0.8 \mathrm{~cm}$. to a diameter of $0.4 \mathrm{~cm}$.

For the first centimeter the vessel travelled in the right atrio-ventricular groove, then broke up into four branches. The first supplied the infundibular heart muscle, the second (Fig. 5, vessel "C") coursed towards the apex for $1.3 \mathrm{~cm}$. and then disappeared into the myocardium to enter the right ventricle by a minute opening through which a nylon suture could just be insinuated. The third branch gave off two small muscular twigs, while the fourth continued normally in the atrio-ventricular groove, giving off a long posterior descending branch and two smaller muscular branches to the posterior aspect of the left ventricle.

At the apex, towards the right of the septum a small vessel $0.3 \mathrm{~cm}$. in diameter appeared suddenly through the muscle to course tortuously for $1.0 \mathrm{~cm}$. along the left heart border. At necropsy, this artery was thought to arise from the apex of the right ventricle but this connection could not be demonstrated conclusively. 
Histology. By serial section it was possible to trace a direct connection between the ventricular lumen and the small coronary vessel " $\mathrm{C}$ " (Fig. 5). The artery continued its course within the heart muscle for some $0.2 \mathrm{~cm}$. before losing its medial coat. This intracardiac portion of the media contained very much more dense elastic tissue than was seen in the extracardiac media. The intimal layer continued, to line the fistula, which terminated at the head of a moderately large intertrabecular sinus, thus establishing direct continuity with the lumen of the ventricle (Fig. 5). Beneath the endothelial lining of the fistulous channel there was a small amount of fibrous and elastic tissue, which increased considerably at the point of junction with other sinusoids. The elastic tissue was always represented by a thin unbroken line just under the endothelium, and where elastic fibres were present in increased numbers they lay outside this lamella.

From a study of the sections on either side of that depicted in Fig. 5 it appeared that numerous sinuses communicated with the fistula at various points along its course although it is probably true to say that the one depicted was the major or thoroughfare channel. Nevertheless it seems likely that the amount of blood entering the ventricle is limited only by the dimensions of the coronary artery, and not by the apparent smallness of size of any one channel.

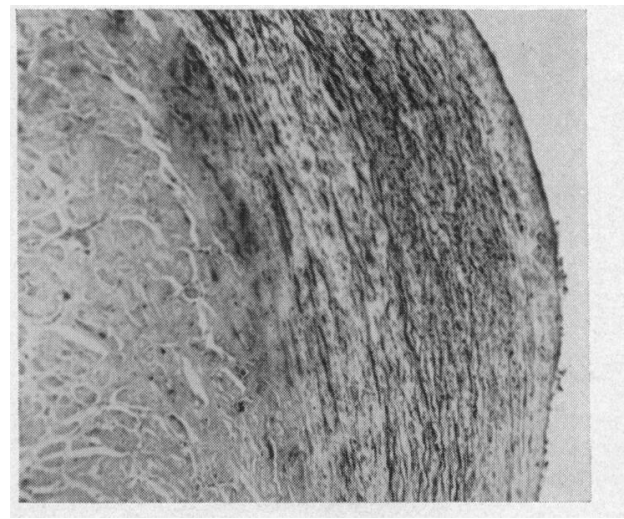

FIG. 4.-Case 1. Square "X" in Fig. 3. Shows the great increase in elastic tissue present in the sub-endocardium opposite the point of debouchment of the fistulous channel. The underlying muscle shows incipient necrosis. (Verhoeff-van Gieson, $\times 150$.)

Case 3. Mdm. Y.G.S., a Teochew, was admitted to the Kandang Kerbau Maternity Hospital, Singapore, and delivered of twins the next day. The second twin was normal; the first, who weighed $3 \mathrm{lb} 12 \mathrm{oz}$., was stillborn.

Necropsy. The heart was of normal size. The right atrium was rather small. There was a very large atrial septal defect $1.5 \mathrm{~cm}$. in diameter. The tricuspid opening was represented by a rigid fibrous ellipse, $5.0 \mathrm{~mm} . \times 3.0 \mathrm{~mm}$., to which rudimentary valve leaflets were attached. The right ventricle was very small, $1.5 \mathrm{~cm} . \times 1.5 \mathrm{~cm} . \times 1.5 \mathrm{~cm}$., and thick-walled $(1.3 \mathrm{~cm}$.): the left was much enlarged $(2.5 \mathrm{~cm} . \times 2.0 \mathrm{~cm} . \times$ $1.5 \mathrm{~cm}$.) and showed moderate fibroelastosis. There was complete atresia of the pulmonary valve. The lungs were supplied by a small patent ductus arteriosus.

From the anterior aortic sinus, a single large coronary vessel (Fig. 6, "D") arose to pass for $1.3 \mathrm{~cm}$. in the right atrio-ventricular groove. At this point the vessel wall became much thicker and the lumen wider, the vessel turning abruptly at right angles to course over the surface of the right ventricle for $1.0 \mathrm{~cm}$. before entering the cavity of the right ventricle by a circular opening $4 \mathrm{~mm}$. across (Fig. 6).

From the aneurysmal bulge, a small branch continued normally in the A-V groove giving off descending branches to the posterior aspect of the ventricles.

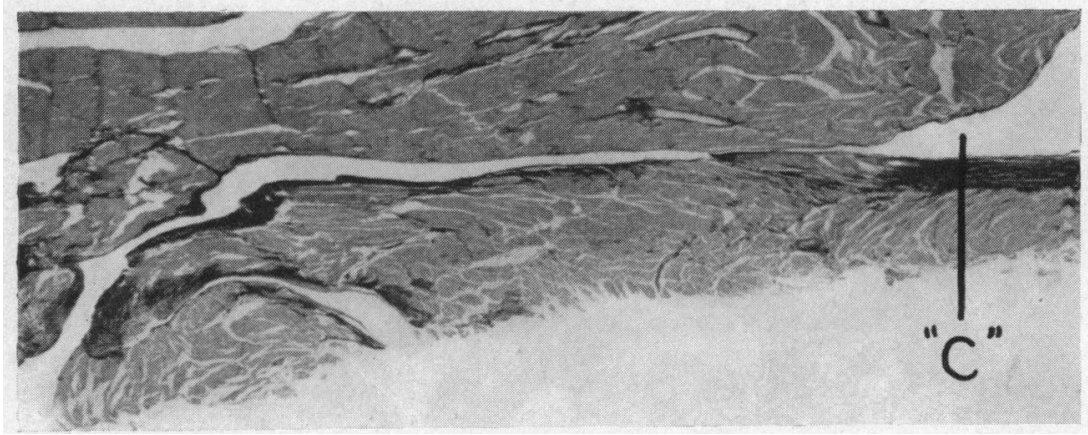

FIG. 5.-Case 2. On the right, a dense black band of elastic tissue marks the point of entry of vessel " $C$ " into the myocardium. There is very rapid narrowing into a sinusoidal channel which is seen to open into the lumen of the right ventricle on the left. (Verhoeff-van Gieson, $\times 6$.) 
On the surface of the heart anteriorly, $2.0 \mathrm{~cm}$. from the atrio-ventricular groove in the region of the interventricular septum, a coronary vessel ("E") arose de novo (Fig. 7). The vessel proceeded towards the left atrio-ventricular groove curving gently upwards, giving off towards the apex three ventricular branches, and ending over the left atrium. It did not appear to communicate with any other vessel.

Histology. Vessel "D" (Fig. 6) showed moderate thickening of the subintima. Near the aorta the media was normal, but between the aneurysmal bulge and the point of entry of the artery into the heart, the amount of muscle slowly diminished as the depth of the subintima increased. The internal elastic lamina was split and fenestrated throughout.

Unfortunately the angle of cut was not favourable, so it was not possible to demonstrate direct continuity in the same plane, between vessel "E" (Fig. 7) and the left ventricular cavity. However, serial sections showed a direct communication between several fairly large endothelium lined sinusoids and the anomalous artery.

Initially, as they opened into the left ventricular cavity, the sinuses were lined by endothelium, but as they linked up within the heart muscle, they gradually acquired a considerable amount of supporting tissue. At first, there appeared increasing numbers of stellate fibrocytes between the endothelium and the usual subjacent thin elastic lamina, which assumed the character of an internal elastic lamina. More and more elastic fibres appeared without it, mingled with increasing numbers of collagen fibres (Fig. 8 and 9).

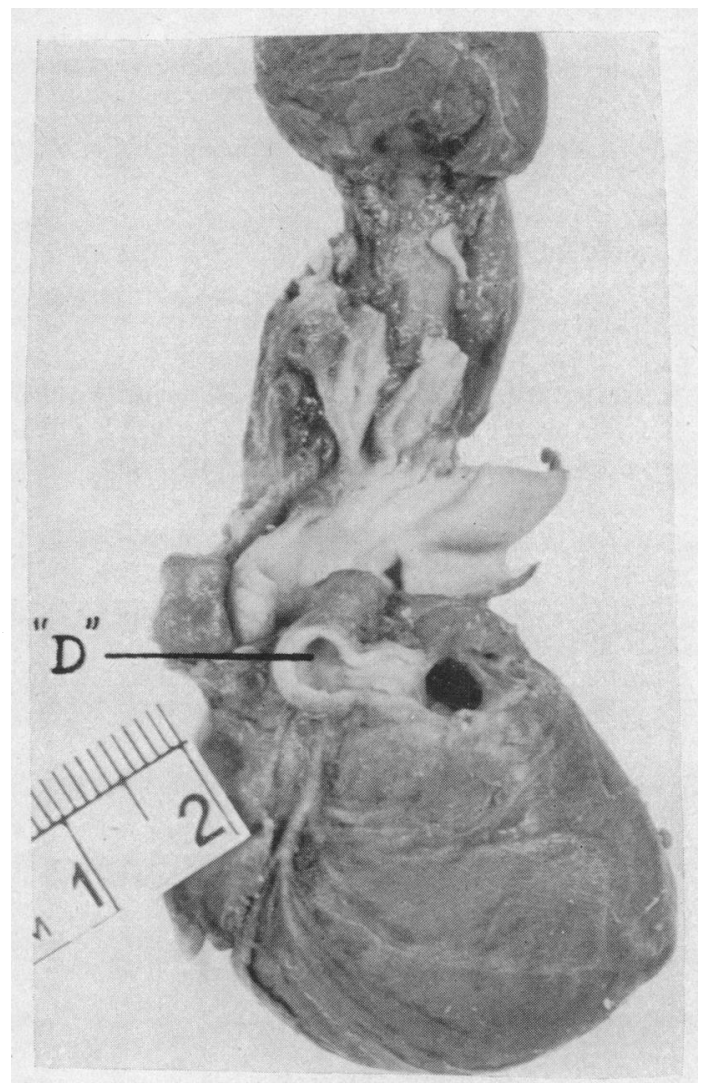

FIG. 6.-Case 3. The heart viewed from behind. Arising from the anterior aortic sinus a single large coronary artery ("D") is seen to terminate, after an abrupt turn, by entering the cavity of the right ventricle. A small branch is seen to continue in the right atrio-ventricular groove.

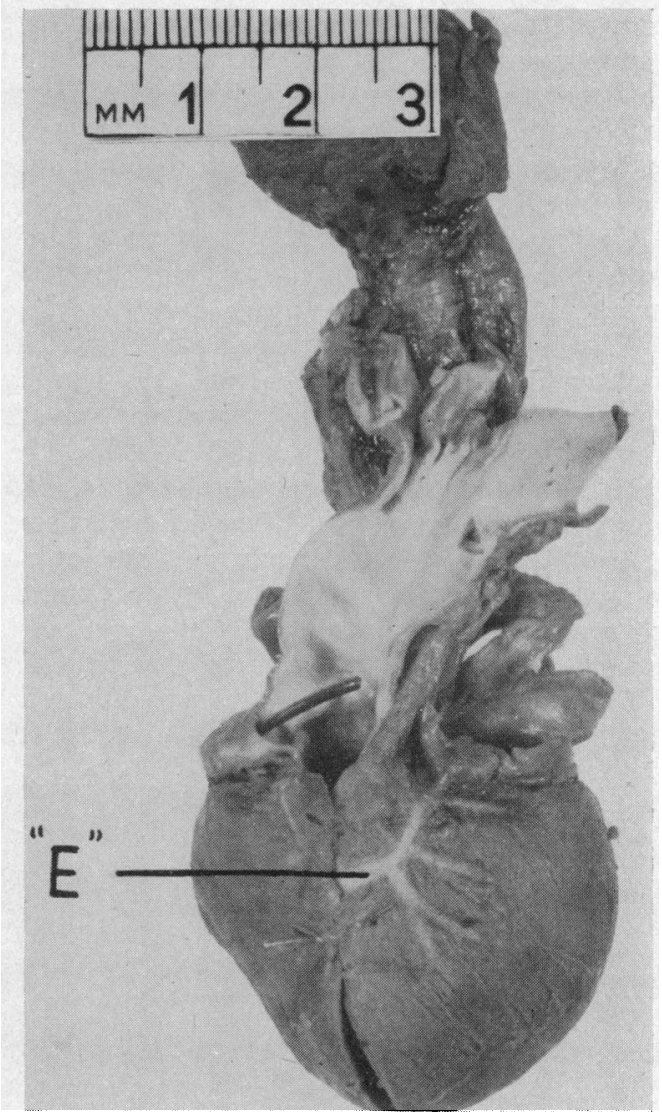

FIG. 7.-Case 3. On the anterior surface of the heart the anomalous vessel " $E$ " is seen to arise de novo to run over the upper half of the left ventricle towards the left atrium. A plastic rod is seen in the anterior coronary sinus, from which vessel " $D$ " originates. 


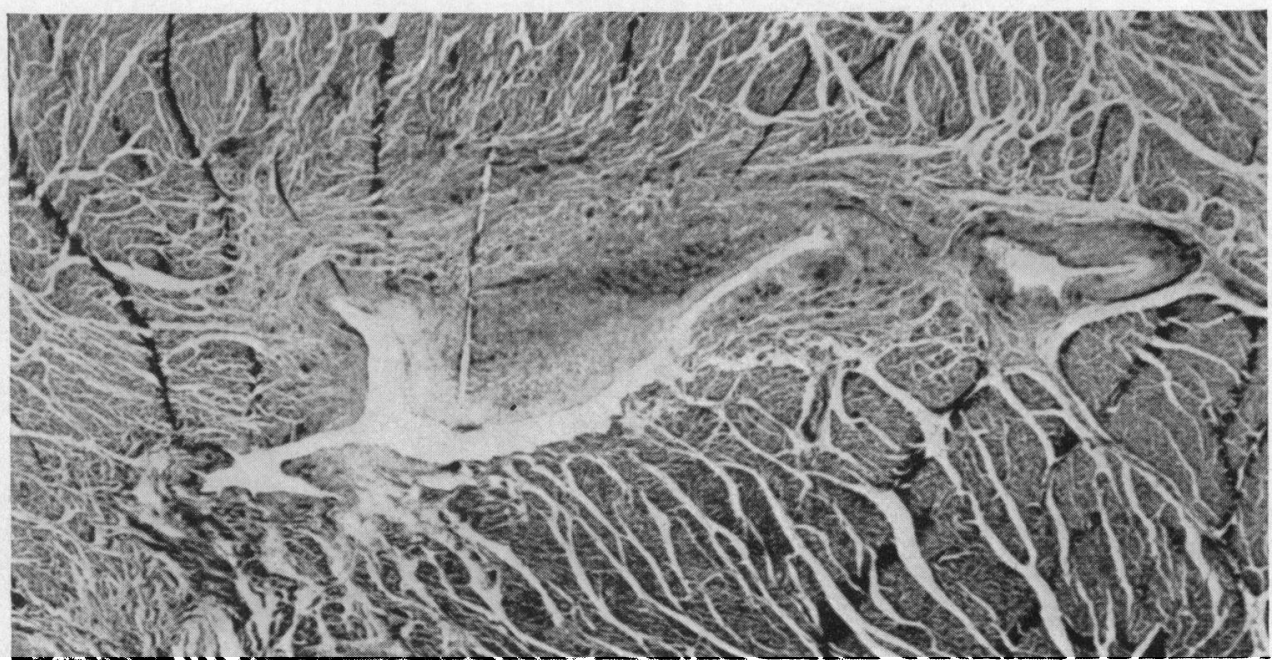

FIG. 8.-Case 3. Shows two sinusoids that have acquired a considerable amount of supporting tissue, mainly elastic and fibrous, about to join up within the left ventricular wall. Note that although that on the left has a fairly thick wall on the upper half of the photomicrograph, the lower wall is still that of a sinusoid. (Verhoeff-van Gieson, $\times 45$.)

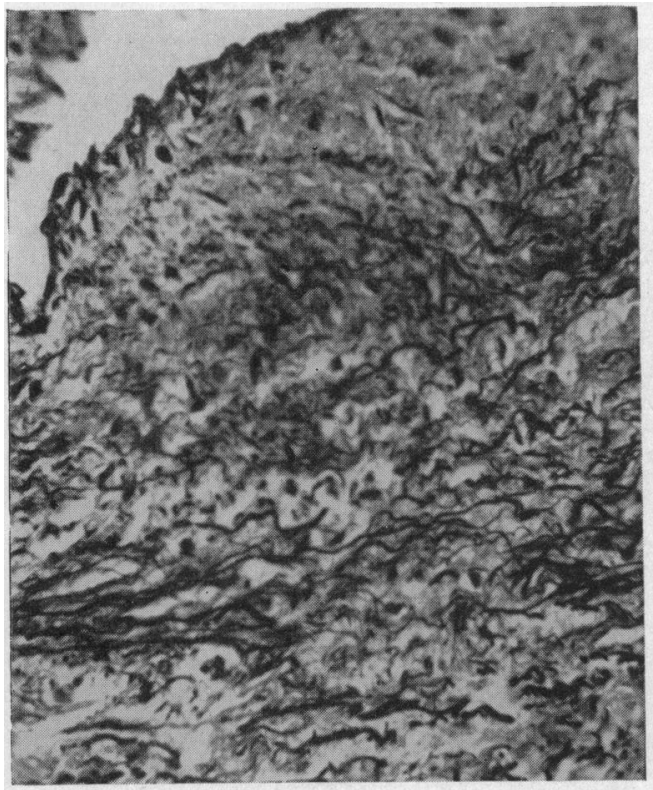

Fig. 9.-Case 3. Shows the presence of an internal elastic lamina, with surrounding collagen and elastic fibres (Verhoeff-van Gieson, $\times 500)$.

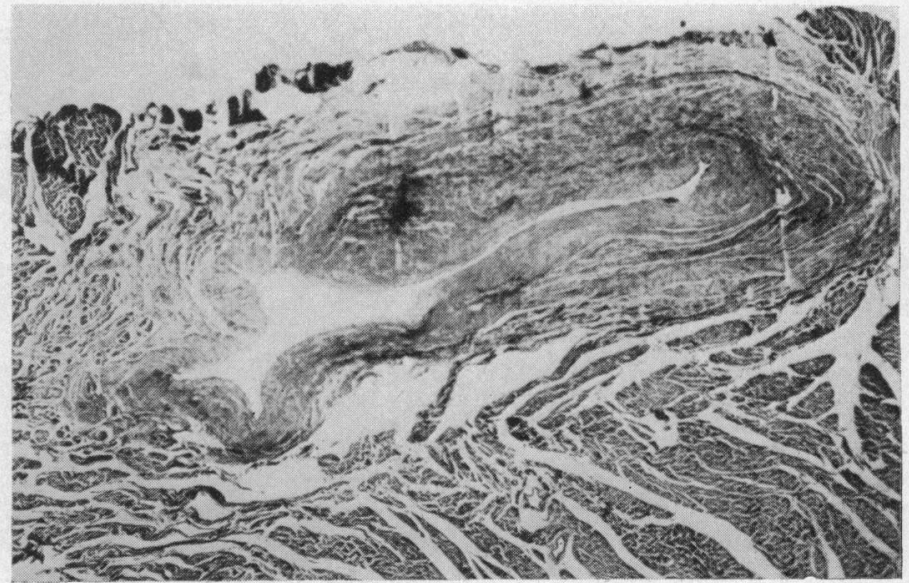

FIG. 10.-Case 3. Shows vessel "E" just below the epicardium, before emerging on the surface of the heart. Serial section 210 (Verhoeff-van Gieson, $\times 45$ ). 
Williams et al. (1951) entitle an appearance similar to that of Fig. 8 (their Fig. 3a) "emptying of a sinusoid ... into the orifice of the anomalous coronary vessel." Gradually muscle fibres appeared, increasing rapidly in number as the vessel reached the surface (Fig. 10). Once on the surface of the heart, vessel "E" (Fig. 7) appeared to be indistinguishable from any other small artery.

\section{COMMENT}

The three cases described, although in general similar to other such fistulæ, are in other respects unique. In Case 1 there was not only a fistula, with at least four channels, from the left coronary artery into the right ventricle, but there was also another from the right coronary artery into the same chamber. No similar case has been described.

In Case 2 there were no unusual features apart from the small vessel that appeared suddenly through the muscle of the cardiac apex. Despite the failure to show communication between this artery and the ventricular lumen, there is little doubt that it did so, particularly in view of the findings in vessel " $C$ " (Fig. 5).

Case 3, in addition to the right coronary artery-right ventricular fistula, showed the extraordinary vessel "E" (Fig. 7) which seemed to sprout from the anterior surface of the heart, and which proved to have sinusoidal communication with the left ventricular chamber. Williams et al. (1951) also describe a vessel that arose de novo from the heart muscle, but this channel, which contained no muscle, communicated with the posterior descending and left circumflex arteries. Vessel "E" was quite autonomous, not anastomosing with any other vessel. It is not unlikely that this artery represents an attempt to compensate for the lack of a left coronary artery, particularly when so much of the right coronary flow was diverted into the right ventricle.

\section{PATHOLOGY}

The anomaly is not confined to man alone. Some five examples have been encountered in cattle, the first recorded being that of Reid (1922). The animal, a healthy three-year-old ox had, on the day of its demise, walked $\frac{3}{4}$ mile from the farm to the abattoir. On examination of the heart, a thin-walled abnormal vessel was observed to arise above the anterior cusp of the aortic valve, passing forward between left atrium and pulmonary artery, giving off a circumflex branch, and continuing along the interventricular septum to the apex, when it dilated into a roughly conical cyst-like structure, $7 \mathrm{~cm}$. broad at the base, and $6 \mathrm{~cm}$. long, the cyst wall being thinner than that of the vessel. The cyst communicated directly with the cavity of the left ventricle by a circular aperture $3.5 \mathrm{~cm}$. across, part of which was filled in by a fibrous tissue diaphragm, the width of the actual opening being $1.5 \mathrm{~cm}$. Histologically the abnormal vessel showed a normal endothelium, a well-marked internal elastica and a variable amount of muscle. The so-called cyst showed a thickened endothelial lining, a little muscle, and loose connective tissue, comparable with the human case of Lovitt and Lutz (1954). Substantially similar cases have been reported by Schöndube (1922) and Rubli (1933). The latter author cites a further two cases.

In man, the following communications have been observed.

Between right coronary artery and right atrium (Harris, 1937; Colbeck and Shaw, 1954; Johnson, 1956; Morrow, 1958; Edwards et al., 1958).

Between right coronary artery and right ventricle (Wilson and Grant, 1925-26; Grant, 1926 (b); Espino Vela et al., 1951; Williams et al., 1951; Lovitt and Lutz, 1954; Herbst and Michel, 1957; Walther et al., 1957; Gasul et al., 1958; Gasul et al., 1959 (two cases)).

Between left coronary artery and right ventricle (Alexander and Green, 1952; Sondergaard, 1955; Davis et al., 1956; Neill and Mounsey, 1958; Munner et al., 1958; Schultz, 1958).

Between left coronary artery and right atrium (Garomella, 1958; Bosher, 1959).

Between left coronary artery and left atrium (Mozen, 1956; Kittle, 1959).

Between left coronary artery and left ventricle (Blakeway, 1918).

There are a few cases whose precise classification is open to question. Gasul et al. (1959) diagnosed the anomaly clinically in a seven-month-old male infant. This was confirmed by venous angiocardiography and cardiac catheterization. The site of fistula was not mentioned.

Trevor (1911) described an 11-year-old girl admitted to hospital with streptococcal septicæmia. 
On admission there was a rough systolic murmur and thrill. Some five days before death another to-and-fro "scratchy" murmur, of maximal intensity over the tricuspid area, was heard. At necropsy there was a fusiform thin-walled aneurysm of the descending branch of the right coronary artery, situated within the muscle of a very thick-walled right ventricle. The coronary artery leading to this was very dilated, being $1.25 \mathrm{~cm}$. in diameter. On the anterior wall of the aneurysm there was an opening $0.6 \mathrm{~cm}$. across leading to the cavity of the right ventricle, the edges of which were rough, and the surrounding endocardium ulcerated. Although this case could be included as an example of a communication between right coronary artery and right ventricle, it seems not unlikely that the communication in the aneurysm was due to the bacteræmia.

The case of Valdivia et al. (1957) is in some respects similar. They describe an extraordinary aneurysm $17 \mathrm{~cm} . \times 23 \mathrm{~cm} . \times 24 \mathrm{~cm}$. situated on the postero-lateral aspect of the left ventricle. This communicated with a tortuous dilated right coronary artery, and with the right atrium by an orifice $0.2 \mathrm{~cm}$. in diameter. As the patient, a 25 -year-old woman, was known to have had a heart murmur from the age of six, the aneurysm was held to be congenital in origin. Whether the fistula was secondary is open to question.

Essenberg (1950) describes an anomalous branch of the left coronary artery in a 22-week-old human fœtus. In essence, three vessels arose from the left posterior aortic sinus. One branch, which he terms the "circumflex", passed directly towards the left atrium, penetrated the left atrial wall, entering that chamber close to the septum primum, to ascend on the medial wall for $4.5 \mathrm{~mm}$. before once more piercing the left atrial wall close to the base of the pulmonary artery. It then passed towards the right atrium, in which chamber it probably terminated.

Steinberg et al. (1958) were able to demonstrate a fistula in a 13-year-old girl by angiography, but could not be certain where it ended. Cooley and Sloan (1956), on angiography, displayed an arteriovenous fistula that probably involved the right coronary artery of a 10-year-old boy.

On occasion the fistula may not involve the coronary arteries at all. Brown and Burnett (1949) found that in addition to a normal left coronary artery, there arose from the left posterior aortic sinus, an abnormal endothelium lined tract which extended to the chamber of the right ventricle. This channel was $0.5 \mathrm{~cm}$. across at its narrowest point, and passed beneath the pulmonary artery to the right of the left coronary artery.

Edwards (1958) separates arteriovenous-like communications of the coronary arteries into two groups. In the first (or secondary type) there is always an associated congenital atresia of either the aortic or pulmonary valve, in the presence of an intact ventricular septum and a competent corresponding atrio-ventricular valve. It is Edward's thesis that under these circumstances blood entering the ventricle proximal to the atretic valve is unable to escape in either a forward or backward direction. Thus trapped, it is driven from the ventricle through myocardial sinusoids towards the epicardium, where the sinusoids converge to form a gross vessel which unites with branches of the coronary arteries. While this may be true in the heart described by Williams et al. (1951) it is very doubtful whether this mechanism was operative in Case 3. Although there was a complete pulmonary valve stenosis, it is very doubtful whether the minute tricuspid leaflets attached to a very firm A-V ring could be described as competent. Certainly in the post-mortem specimen the leaflets, although morphologically normal, were very taut and could not be approximated. Indeed, Edwards (1958) gives as a type example for this group the case of Blakeway (1918). While in this latter specimen there was complete aortic valve atresia, an intact interventricular septum, and a communication between the left coronary artery and the left ventricle, there was a gross abnormality of the mitral valve.

To quote Blakeway (1918), "the left ventricle ... is of approximately normal size, and has a well-developed muscular wall; but in almost all other respects it is a highly abnormal chamber. Its upper sixth part is partially separated from the rest by a prominent oblique muscular ridge ... columnæ carneæ, though small, are prominent features of the ridge and of the upper subdivision of the cavity: certain of them are developed into musculi papillares, which have attached to them the chordæ tendineæ belonging to the two tiny cusps of the mitral valve . . . in the lower subdivision the 
endocardium is smooth. ..." In the light of this one wonders if the valve was, in fact, competent.

Edward's second group, in which there are no associated cardiac defects, embraces not only arterio-cameral fistulae but also anomalous communications between coronary artery and the pulmonary trunk, as well as anomalous origin of one coronary artery from the pulmonary artery. As he rightly points out, such anomalies have one feature in common: they give rise to shunts, and it is the size of the shunt which determines the degree of cardiac embarrassment.

Most cases have shown some dilatation of the abnormal vessel. This may be generalized, affecting the entire length or a major portion of the vessel (Harris, 1937; Espino Vela et al., 1951; Williams et al., 1951; Davis et al., 1956; Herbst and Michel, 1957), or it may be confined to a segment, the resulting aneurysm being, as a rule, fusiform. Both generalized and aneurysmal dilatation may be found in the same vessel (Colbeck and Shaw, 1954). The focal aneurysm may be found at any point along the artery. The abnormal vessel usually lies just under the epicardium, but a portion of its length may be found within the ventricular muscle (Blakeway, 1918).

Some writers have considered the concomitant aneurysm, rather than the arterio-cameral fistula, to be the primary lesion (Lovitt and Lutz, 1954; Mozen, 1956). This is understandable if there is a fistulous opening in the aneurysmal wall, as in the cases of Valdivia et al. (1957) and Edwards et al. (1958), but most authorities would agree with Plachta and Speer (1958) who believe that a uniform vascular ectasia secondary to an anomalous coronary artery fistula should not be regarded as an example of a coronary artery aneurysm.

\section{HistologicAL Findings}

The "abnormal" vessel may on section prove to be indistinguishable from the normal coronary artery (Blakeway, 1918; Davis et al., 1956). Usually there is a defect in one or more coats, generally the elastic laminæ: these may be fragmented (Edwards et al., 1958) or reduplicated (Harris, 1937). Often the microscopic appearances have been obscured by atheroma and calcification. Destruction, absence, or diminution in the amount of the medial muscle are common findings.

Williams et al. (1951), on serial sectioning, showed direct continuity by sinusoidal connection between the lumen of the right ventricle and the lumen of the anomalous vessel. As the zone of transition from sinusoids to vessel was reached, a gradual thickening of the fibro-elastic layer occurred pari passu with gradual addition of an outer collagenous layer (Fig. 8, 9, and 10). In this vessel, however, no muscle was demonstrated.

The histological findings in the present, and other, cases appear to confirm the views of Grant (1926b) who related the case of a 14-month-old girl with pulmonary valve atresia. The right atrium was much enlarged, the tricuspid valve showing two deformed curtains. On the upper aspect of the heart, beneath the right atrial appendage, a small firm, rounded nodule, $6 \mathrm{~mm}$. in diameter, was seen beneath the pericardium. The ventricular wall in this region was very thick, containing much fibrous tissue and many blood-filled spaces. The coronary vessels were normal. Reconstruction, after serial sectioning, showed that the nodule communicated with the coronary arteries, the enlarged trabecular sinuses, the veins, and the capillaries, as well as with the ventricular lumen. Histologically, there was a condensation of elastic tissue beneath the endothelium lining the intramuscular sinuses (Fig. 3, 5) forming an internal elastic lamina, beneath which, in several places, there were small amounts of smooth muscle.

Grant, by virtue of his work on the embryology of the coronary vessels (Grant, 1926a), and later on the Thebesian veins (Grant and Viko, 1930), thought that such anomalies represented persistence of the intra-muscular sinusoids found in the developing heart. Normally there is protrusion of endothelium-lined sinusoids from the cavity of the developing ventricle, which join up with inter-trabecular spaces. The outer trabecular spaces, initially large and extending to the epicardium, by virtue of development of the heart muscle become narrowed into capillaries, which at a later date link up with the developing coronary arteries and veins. The inner intertrabecular channels retain their continuity with the lumen of the heart becoming the Thebesian vessels. 
While in those hearts with atresia of either of the outflow valves there is likely to be an increase in the intra-ventricular pressure tending to keep the sinusoids open, this does not account for the genesis of primary fistulæ. The only case for which a definite ætiology has been suggested, is that of Schultz (1958): the mother of his patient was known to have had a severe attack of rubella in the early months of pregnancy, and the child was noted to be blind in the right eye when four weeks old, the heart lesion being noticed at the age of three years.

\section{Diagnosis AND TREATMENT}

Although arterio-cameral fistulæ may involve differing chambers and arteries there is a remarkable similarity in the physical signs. There is usually a harsh præcordial murmur, which has been described as continuous (Munkner et al., 1958; Edwards et al., 1958); machinery-like (Brown and Burnett, 1949; Davis et al., 1956); as having a "peculiar superficial quality" in late systole and maximal in early diastole (Steinberg et al., 1958; Neill and Mounsey, 1958); or as loud and continuous to-and-fro with systolic accentuation, best heard at the pulmonary area (Mozen, 1956), or Hin-und Her-Gerausch (Herbst and Michel, 1957). Generally the murmur is best heard, and the associated thrill felt, in the fourth and fifth left intercostal spaces between the sternal border and cardiac apex. It may, however, be most prominent at the pulmonary area (Davis et al., 1956; Mozen, 1956).

It is noteworthy that this murmur has been considered by most clinicians to be that of a patent ductus arteriosus, if not entirely typical. The differential diagnosis includes aortico-pulmonary septal defect, rupture of an aneurysm of the aortic sinus, ventricular septal defect with aortic regurgitation, or an anomalous communication between aorta and right ventricle such as that described by Brown and Burnett (1949).

Nearly all patients with a sizeable shunt, in addition to a systolic murmur, have a diastolic murmur, the localization of which corresponds fairly well to that of the arteriovenous communication (Shultz, 1958). A diastolic murmur was not heard in the case reported by Trevor (1911) until the shunt had formed, and proved to be localized to the shunt site.

The electrocardiogram has been normal (Davis et al., 1956; Schultz, 1958; Mozen, 1956; Steinberg et al., 1958), difficult to interpret (Edwards et al., 1958), or has shown bundle-branch block (Espino Vela et al., 1951; Colbeck and Shaw, 1954).

Cardiac catheterization has suggested a high ventricular septal defect (Davis et al., 1956; Munkner et al., 1958). Schultz (1958) correctly interpreted the findings in his case as indicating two shunts, one from the aorta to the pulmonary artery (patent ductus arteriosus) and the other from the left to the right ventricle (the abnormal vessel). Aitken (1959) was able to diagnose an arteriovenous fistula, in a patient with clinical findings essentially the same as those of an arterio-cameral fistula, by the raised oxygen content of the blood in the coronary sinus. The abnormal vessel has been demonstrated by angiography (Steinberg et al., 1958; Neill and Mounsey, 1958) and by retrograde aortography (Morrow, 1958; Munkner et al., 1958; Gasul et al., 1959).

Once infancy is passed, the entity need not be serious. Survival to the age of 80 , before the advent of signs of heart failure, has been recorded (Colbeck and Shaw, 1954). In the 37-year-old man seen by Harris (1937) death was due to a sudden hæmorrhage into a brain tumour, the arterio-cameral fistula being quite unsuspected in life. Herbst and Michel (1957) remark that their 8-year-old patient who, in addition to a fistula between right coronary artery and infundibulum of the right ventricle, exhibited Fallot's tetralogy with valvular pulmonary stenosis, was, despite prognostications that she would never walk, "wild und unruhig."

It seems reasonable, however, to attempt to obliterate the fistulous vessel, especially in the young, to avert subsequent possible heart failure or bacterial endocarditis. Schultz (1958) dissected free the afferent artery to the aneurysmal swelling, then clamped it, watching the electrocardiogram and the myocardium for a further ten minutes: as nothing untoward occurred, the vessel was ligated and the aneurysm obliterated by silk sutures tied over gelatine sponge. Herbst and Michel (1957) were not so fortunate: after correcting a valvular pulmonary stenosis and exploring with 
the fifth finger the point of entry of the abnormal vessel into the anterior wall of the infundibulum, they proceeded to tie off the abnormal channel: the heart soon stopped, and was only persuaded to restart after considerable manipulation. They felt that this arrest of the cardiac action might have been due to muscle anoxia, as the abnormal vessel had one small branch that supplied the infundibulum. Their patient eventually made a good recovery. Davis et al. (1956) removed a small segment of the artery; Morrow (1958) and Mozen (1956) closed the vessel at the point of entry into the atrium; and Johnson (1956) occluded it by multiple sutures.

\section{SUMMARY}

Three cases of communication between coronary artery and heart chamber are described, all in Chinese children. The cases of this anomaly that have been reported are classified, and the histological findings are discussed in the light of these and of theories of the ætiology.

Diagnosis and treatment are briefly reviewed and the name "arterio-cameral fistula" is suggested to differentiate this lesion from other arteriovenous communications of the heart.

I wish to thank Professor R. Kirk for kind help and encouragement, Drs. T. Balasingham, E. B. La'Brooy, and $\mathrm{Ng}$ Chiau Gian for access to their post-mortem notes and material, Mr. V. M. Chacko for the sections, Mr. V.Nalpon for the photographs, Mr. Ti Teow See for the drawing, and Mr. P. A. Samuel for typing the script.

\section{REFERENCES}

Aitken, G. J. (1959). Scot. med. J., 4, 27.

Alexander, W. S., and Green, H. C. (1952). A.M.A. Arch. Path., 53, 187.

Blakeway, H. (1918). J. Anat. Physiol., 52, 354

Bosher, L. H. (1959). Quoted by Gasul et al. (1959).

Brown, R. C., and Burnett, J. D. (1949). Pediatrics, 3, 597.

Colbeck, J. C., and Shaw, J. M. (1954). Amer. Heart J., 48, 270.

Cooley, R. N., and Sloan, R. D. (1956), in Radiology of the Heart and Great Vessels, p. 226. Baltimore, Williams and Wilkins.

Davis, C., Jr., Dillon, R. V., Fell, E. H., and Gasul, B. M. (1956). J. Amer. med. Ass., $160,1047$.

Edwards, J. E. (1958). Circulation, 17, 1001. , Gladding, T. C., and Weir, A. B. (1958). J. thoracic Surg., 35, 662.

Espino Vela, J., Velazquez, T., and Fuenmayor, A. (1951). Arch. Inst. cardiol. Mexico, 21, 686.

Essenberg, J. M. (1950). Anat. Rec., 108, 709.

Garomella, J. J. (1958). Personal communication to Edwards et al. (1958).

Gasul, B. M., Fell, E. H., and Dillon, R. F. (1958). Personal communication to Edwards et al. (1958).

-, Moreano, M., and Weinberg, M., Jr. (1959). A.M.A. Arch. Surg., 78, 203.

Grant, R. T. (1926a). Heart, 13, 261. (1926b). Heart, 13, 273.

- and Viko, L. E. (1930). Heart, 15, 103.

Harris, P. N. (1937). Amer. J. Path., 13, 89.

Herbst, M., and Michel, D. (1957). Zschr. Kreislaufforsch., 46, 538.

Johnson, J. (1956). Personal communication to Davis et al. (1956).

Kittle, C. F. (1959). Quoted by Gasul et al. (1959).

Lovitt, W. V., Jr., and Lutz, S., Jr. (1954). A.M.A. Arch. Path., 57, 163.

Morrow, A. G. (1958). Personal communication to Edwards et al. (1958).

Mozen, H. E. (1956). Ann. Surg., 144, 215.

Munner, T., Petersen, O., and Vesterdal, J. (1958). Acta. Radiol., 50, 333.

Neill, C., and Mounsey, P. (1958). Brit. Heart J., $20,61$.

Plachta, A., and Speer, F. D. (1958). A.M.A. Arch. Path., 66, 210.

Reid, C. (1922). J. Anat. Physiol., 57, 12.

Rubli, H. (1933). Anat. Anz., 77, 169.

Schöndube, W. (1922). Frankfurt. Ztschr. Path., 27, 197.

Schultz, J. (1958). Amer. Heart J., 56, 431.

Sondergaard, T. (1955). Cited by Steinberg et al. (1958).

Steinberg, I., Baldwin, J. S., and Dotter, C. T. (1958). Circulation, 17, 372.

Trevor, R. S. (1911). Proc. Roy. Soc. Med., 5, (section for the study of disease in children), 20.

Valdivia, E., Rowe, G. G., and Angevine, D. M. (1957). A.M.A. Arch. Path., 63, 168.

Walther, R. J., Starkey, G. W. B., Zervopoulos, E., and Gibbons, G. A. (1957). Amer. J. Med., $22,213$.

Williams, R. R., Kent, G. B., Jr., and Edwards, J. E. (1951). A.M.A. Arch. Path., 52, 480.

Wilson, J. G., and Grant, R. T. (1925-26). Heart, 12, 295. 